\title{
OS MERCADORES DA EDUCAÇÃO E AS CONCEPÇÕES EMPRESARIAIS PRESENTES NOS PROGRAMAS DE EDUCAÇÃO INTEGRAL
}

\author{
Marilsa Miranda de Souza ${ }^{1}$ \\ Gabriel Henrique Miranda Soares²
}

\begin{abstract}
RESUMO
O objetivo deste trabalho é analisar as concepções teóricas dos programas de educação integral no Brasil enquanto orientações e formulações dos organismos internacionais e do setor privado. Estes, com o discurso de melhorar a qualidade da educação, colocaram na agenda das políticas públicas a necessidade de ampliação da jornada escolar. Utilizou-se o método do materialismo históricodialético instrumentalizado na pesquisa bibliográfica e documental, por meio da qual constatamos as parcerias com entidades do setor privado desde a etapa inicial até a implementação da política de educação integral. Destacam-se as ações do movimento Todos pela Educação (TPE) e suas proposições desde o Plano de Metas Compromisso Todos pela Educação à implantação do Plano de Desenvolvimento da Educação (PDE) e as políticas dele decorrentes. As concepções dos programas de educação integral, reproduzidas por meio da Pedagogia das Competências, contemplam os postulados das pedagogias liberais pós-modernas e dissemina a ideologia do Terceiro Setor em conceitos empresariais como empoderamento, empreendedorismo, economia solidária, etc., com o objetivo de formar trabalhadores como capital humano, adaptados às demandas do sistema produtivo.
\end{abstract}

Palavras-chave: Educação integral. Concepções empresariais. Pedagogias das competências.

\section{THE MERCHANDISES OF EDUCATION AND THE BUSINESS CONCEPTIONS PRESENT IN THE INTEGRAL EDUCATION PROGRAMS}

\begin{abstract}
This paper aims to analyze the theoretical conceptions of integral education programs in Brazil as guidelines and formulations of international organizations and

1 Doutora em Educação Escolar - (UNESP-Campus de Araraquara). Professora do Departamento de Ciências da Educação da Universidade Federal de Rondônia-UNIR e do PPGE/UNIR- Campus José Ribeiro Filho-Porto Velho-RO. E-mail: marilsa.miranda@unir.br

2 Mestre em Educação (UNIR), Mestre em História e Estudos Culturais (UNIR). Professor substituto do Departamento de História da Universidade Federal de Rondônia (UNIR), Campus de Rolim de Moura-RO. E-mail: gabrielhmsoares@gmail.com
\end{abstract}


the private sector. These, with the discourse of improving the quality of education, have placed on the public policy agenda the need to extend the school day. The method of historical-dialectical materialism was used in bibliographical and documentary research, through which we verified the partnerships with entities of the private sector from the initial stage until the implementation of the Policy of integral education. The actions of the All for Education (TPE) movement and its proposals from the Plan of Commitment All for Education to the implementation of the Education Development Plan (PDE) and the resulting policies are outstanding. The conceptions of integral education programs, reproduced through the Pedagogy of Competences, contemplate the postulates of postmodern liberal pedagogies and disseminate the ideology of the Third Sector in entrepreneurial concepts such as empowerment, entrepreneurship and solidarity economy with the aim of training workers as human capital adapted to the demands of the productive system.

Keywords: Integral education. Business conceptions. Competence pedagogies.

\section{LOS MERCADELES DE LA EDUCACIÓN Y LAS CONCEPCIONES EMPRESARIALES PRESENTES EN LOS PROGRAMAS DE EDUCACIÓN INTEGRAL}

\section{RESUMEN}

El objetivo de este trabajo es analizar las concepciones teóricas de los programas de educación integral en Brasil como orientaciones y formulaciones de los organismos internacionales y del sector privado. Estos, con el discurso de mejorar la calidad de la educación, colocaron en la agenda de las políticas públicas la necesidad de ampliación de la jornada escolar. Se utilizó el método del materialismo histórico-dialéctico instrumentalizado en la investigación bibliográfica y documental, por medio de la cual constatamos las alianzas con entidades del sector privado desde la etapa inicial hasta la implementación de la Política de educación integral. Se destacan las acciones del movimiento Todos por la Educación (TPE) y sus proposiciones desde el Plan de Metas Compromiso Todos por la Educación a la implantación del Plan de Desarrollo de la Educación (PDE) y las políticas de él derivadas. Las concepciones de los programas de educación integral, reproducidas por medio de la Pedagogía de las Competencias, contemplan los postulados de las pedagogías liberales posmodernas y disemina la ideología del Tercer Sector en conceptos empresariales como empoderamiento, emprendimiento, economía solidaria, etc., con el objetivo de formar trabajadores como capital humano, adaptados a las demandas del sistema productivo.

Palabras clave: Educación integral. Concepciones empresariales. Pedagogías de las competências.

\section{INTRODUÇÃO}

$\mathrm{Na}$ história da educação brasileira percebe-se uma constante mudança no que se refere às políticas públicas educacionais, dentre elas 
destacam-se as políticas de educação integral. A educação integral apresenta conceitos variados, de acordo com as concepções organizadas em distintos períodos históricos, diretamente relacionados às relações socioeconômicas.

Para analisar as políticas educacionais no Brasil, primeiramente, se faz necessário identificar suas relações macroeconômicas no contexto do capitalismo em sua fase imperialista. O fenômeno do imperialismo ocorreu no final do século XIX e modificou por completo a ordem capitalista mundial, especialmente nos países dominados (colônias e semicolônias), bastante atrasados em relação aos grandes centros industriais dos países hegemônicos. O imperialismo determina os novos interesses da burguesia mundial e suas ações passam a ser a busca pelo lucro máximo, por meio da exportação de mercadorias e de capitais. Para isso, busca agir sobre os países atrasados para ampliar o número de consumidores de mercadorias e, principalmente, saquear suas matérias-primas e recursos naturais que the garantam maior acumulação de capital. Esses mecanismos utilizados pelo imperialismo garantem a dependência tanto de colônias, por meio da ocupação do território pela potência estrangeira, como de semicolônias, que se caracterizam pelo processo de submissão à potência estrangeira, com esta controlando a estrutura e os aparelhos do Estado, as políticas públicas, os mecanismos de regulação financeira, de empréstimos para infraestrutura, etc., o que resulta na mais completa perda da soberania política da nação (LÊNIN, 1979). Identificamos o Brasil como um país de capitalismo burocrático ${ }^{3}$ que é o tipo de capitalismo engendrado pelo imperialismo nos países atrasados (semifeudal e semicolonial) mediante 0 domínio do imperialismo sobre toda a sua estrutura econômica e social (SOUZA, 2014).

\footnotetext{
${ }^{3}$ O conceito de capitalismo burocrático foi desenvolvido por Mao Tsetung, ao analisar o processo de dependência e atraso do capitalismo chinês, identificando que tal país mantinha relações com os grandes latifundiários e o imperialismo. Esse conceito foi aprofundando por outros teóricos marxistas que o seguiram. Guzmán (1974, p. 1) define o capitalismo burocrático como "[...] o capitalismo que o imperialismo impulsiona num país atrasado; o tipo de capitalismo, a forma especial de capitalismo, que impõe um país imperialista a um país atrasado, seja semifeudal, semicolonial".
} 
A dominação imperialista ocorre de várias formas, dentre elas, destaca-se a atuação de organismos internacionais vinculados às grandes potências econômicas, como o Banco Mundial, a Organização Mundial do Comércio, o Fundo Monetário Internacional, a UNESCO, etc. Para garantir a dominação econômica é preciso garantir o domínio cultural e ideológico, razão pela qual o imperialismo age no campo da educação. Ao perceber os perigos que a situação de extrema pobreza poderia gerar à manutenção do modo de produção capitalista e às finalidades que a educação poderia apresentar na contensão dos processos revolucionários e ao mesmo tempo garantir a lucratividade, os organismos internacionais passaram a direcionar as políticas educacionais brasileiras e os setores sociais em modo geral. Trabalho e educação caminham indissociavelmente, guiados pelas concepções empresariais, com o intuito de atender aos ajustes necessários ao modo capitalista de produção em crise aguda, própria de sua fase final.

Com o discurso de melhorar a qualidade da educação, os organismos internacionais em parceria com o setor privado no Brasil colocaram na agenda das políticas públicas, a necessidade de ampliação da jornada escolar que se materializou nos programas Mais Educação e Novo Mais Educação (Ensino Fundamental), Ensino Médio Inovador e Fomento às Escolas de Educação Integral no Ensino Médio (Ensino Médio).

Em 2007, no setor das ações do Programa de Desenvolvimento da Educação (PDE), foi instituído por meio da Portaria Interministerial n. ${ }^{\circ} 17$ o Programa Mais Educação, que tinha por objetivo fomentar a Educação Integral de crianças, adolescentes e jovens, por meio de atividades socioeducativas, no contraturno escolar, articuladas ao projeto de ensino desenvolvido pela escola. O Programa Mais Educação foi extinto em 2016 pelo gerenciamento de Temer e em seu lugar foi instituído o Programa Novo Mais Educação, através da Portaria n 1.144, de 10 de outubro de 2016.

As propostas de educação integral não se restringiram ao ensino fundamental. Por meio do programa Ensino Médio Inovador (ProEMI) instituído pela Portaria n 971, de 9 de outubro de 2009, o Governo Federal buscou realizar a reestruturação dos currículos do Ensino Médio. No ano de 
2016 com o objetivo de intensificar a implantação da educação integral nas escolas públicas da rede estadual, institui-se o Programa de Fomento às Escolas de Ensino Médio em Tempo Integral, por meio da Portaria $n^{\circ} 1.145$, de 10 de outubro de 2016, atuando em conformidade com a arbitrária medida provisória $n^{\circ}$ 746, de 22 de setembro de 2016, assinada pelo presidente de turno, Michel Temer.

As pesquisas sobre esses programas apresentam como objetivo central apenas a ampliação da jornada escolar com vistas a garantir, supostamente, a segurança de crianças, adolescentes e jovens em tempo integral afastando-os da criminalidade e dos perigos das ruas. Atuam como paliativas aos problemas sociais buscando mascarar os antagonismos de classes e as relações concretas e contraditórias incentivando as ações individuais e solidárias para amenizar a espoliação capitalista (SILVA; SILVA, 2014; TRENTINI, 2017; ALEPRANDI, 2017; SILVA, 2017).

Assim, o objetivo deste trabalho é analisar as concepções teóricas dos programas de educação integral, enquanto orientações e formulações dos organismos internacionais e do setor privado que atua no aparelho do Estado nos últimos anos. Faremos um esforço para demonstrar como os programas de ampliação do tempo escolar estão articulados aos interesses empresariais. Para desenvolvê-lo utilizamos o método do materialismo histórico-dialético, de forma a desvelar as contradições essenciais do fenômeno, que se fixa na essência, no mundo real, no conceito, na consciência real, na teoria e ciência (KOSIK, 1976, p. 16). Utilizamos como fontes de dados a pesquisa bibliográfica e a análise documental. Por meio da pesquisa bibliográfica fizemos um levantamento da literatura a respeito dos programas de educação integral em curso no Brasil e em seguida uma análise teórica das concepções dos programas a partir da legislação, dos Manuais, Cadernos, documentos orientadores, entre outros textos de referência dos programas de Educação Integral.

A educação integral pode ser defendida a partir de diferentes matrizes ideológicas: concepção libertária construída pelos anarquistas, a concepção liberal desenvolvida no seio da Escola Nova, a concepção 
integralista, concebida pelo movimento conhecido como integralismo na década de 1930 e a concepção socialista desenvolvida com base na teoria marxista e nas experiências da educação socialista (SOUZA; ALEPRANDI; TRENTINI, 2016). A análise bibliográfica e documental revelou que a concepção hegemônica que fundamenta os programas de educação integral implantados na educação básica é o escolanovismo/tecnicismo que se apresentam numa configuração pós-moderna, pois as reorganizações curriculares propostas demonstram o esvaziamento curricular do ensino, reduzido ao imediatismo útil que desconsidera os conhecimentos universais.

\section{AS POLÍTICAS DE EDUCAÇÃO INTEGRAL NA ATUALIDADE E AS DIRETRIZES DOS ORGANISMOS INTERNACIONAIS}

Em1989, a Mesa Redonda Europeia dos Industriais apresentou um relatório com as necessidades de associar a educação às necessidades da indústria. A educação deveria ter conteúdos flexíveis, para uma formação polivalente e a escola deveria ser desregulamentada de forma a acompanhar rapidamente as transformações que ocorrem no sistema produtivo (MAUÉS, 1995, p. 14).

Esse objetivo foi discutido em conferências regionais organizadas pela Unesco e ampliado na Conferência Mundial sobre Educação para Todos, ocorrida em março de 1990, em Jomtien (Tailândia), financiada por quatro organismos internacionais: a UNESCO, o Fundo das Nações Unidas para a Infância (UNICEF), o Programa das Nações Unidas para o Desenvolvimento (PNUD) e o Banco Mundial (BM). Essa conferência foi o marco inicial das reformas socioeducacionais implantadas nos países semicoloniais, inclusive no Brasil. Após a Conferência de Jomtiem, a UNESCO convocou especialistas de todo o mundo para compor a Comissão Internacional sobre Educação para o século XXI, coordenada pelo seu presidente, O francês Jacques Delors. Nasce, assim, o Relatório Jacques Delors: Educação, um tesouro a descobrir (1998). Esse relatório complementou e aprimorou as diretrizes propostas pelos organismos internacionais, fortaleceu as bases teóricas das 
pedagogias pragmáticas, servindo para fundamentar as politicas educacionais em curso na atualidade.

O documento básico do Banco Mundial elaborado para a Conferência Mundial sobre Educação para Todos expressa com objetividade que a educação deve difundir ideologias e um comportamento individual definido pelo centro de inteligência do imperialismo, que, dentre outras questões, destaca os hábitos de consumo e de adaptação às tecnologias que possam garantir uma maior extração de lucros das semicolônias. Para isso, a educação deve formar capital humano para atuar num sistema produtivo reestruturado, conforme as novas técnicas de exploração do trabalho.

La cantidad de adultos de los países em desarrollo com el nível de instrucción necesario para producir, adquirir, adaptar y aplicar las tecnologias modernas a la producción agrícola industrial es peligrosamente baja (BANCO MUNDIAL, 1990, p. 12).

O documento afirma que "las nuevas tecnologias y los nuevos métodos de producción, dependen de uma fuerza laboral bien qualificada e intelectualmente flexible" (BANCO MUNDIAL, 1990, p. 2).

No Brasil, partir de 1990, todas as políticas educacionais passaram a observar as diretrizes impostas pelo imperialismo por intermédio das suas agencias multilaterais, em especial, O Banco Mundial, a UNESCO e a Comissão Econômica para a América Latina e o Caribe (CEPAL). Essas orientações são guiadas pela lógica de mercado e controladas por meio de avaliações e de definições de prioridades e estratégias, na formulação de legislação, no investimentos/financiamento de programas que se articulam ao ideário pós-moderno, fundado nas pedagogias pragmáticas norte americanas do "aprender a aprender" que foram propagadas e hegemonizadas no Brasil a partir desse período. 


\section{O MOVIMENTO TODOS PELA EDUCAÇÃO E SUA INFLUÊNCIA NA FORMULAÇÃO DAS POLÍTICAS PÚBLICAS DE EDUCAÇÃO INTEGRAL}

Para que isso se efetivasse a proposta educacional do grande capital, uma das principais medidas foi a participação do setor privado nas instâncias institucionais. Difundiu-se a ideia de que o sucesso da educação dependeria do envolvimento de "todos" (indivíduos e organizações). Nesse contexto, surgem organizações de grupos empresariais e lideranças da sociedade, atuando em rede, que buscam interferir nas políticas públicas. A justificativa para a inserção do setor privado no setor público educacional são os baixos resultados e a péssima colocação dos estudantes em exames internacionais que acarretam em consequências para o desenvolvimento e a coesão social, especialmente nos países semicoloniais.

Foi nesse contexto que nasceu no Brasil o Movimento Todos pela educação ${ }^{4}$, com o objetivo de reorientar a educação básica. O TPE foi criado, em 2006 e sintetiza a agenda do capital para a educação: a formação de competências e habilidades dos trabalhadores para servirem aos interesses do mercado, definição de metas de desempenho da educação básica por meio do Índice de Desenvolvimento da Educação Básica (IDEB) e avaliação institucional. Organizada pela Fundação Lemann5, o movimento Todos pela Educação (TPE) é uma Organização da Sociedade Civil de Interesse Público (Oscip) que se propõe ser "apartidário e plural", congrega representantes de diferentes setores da sociedade. É composto pelas empresas mantenedoras e parceiras. As mantenedoras do TPE são as seguintes fundações e empresas: DPaschoal, Fundação Bradesco, Fundação Itaú Social, Fundação Telefônica Vivo, Gerdau, Instituto Camargo Corrêa,

\footnotetext{
${ }^{4}$ Todos pela Educação (TPE) é uma organização sem fins lucrativos composta por diversos setores da sociedade brasileira com o objetivo de assegurar o direito à Educação Básica de qualidade para todos os cidadãos até 2022, ano que se comemora o bicentenário da independência do Brasil. Fundado em 2006, o movimento conta com dezenas de organizações, entre mantenedores e parceiros, divididos entre os diversos cargos da estrutura organizacional do TPE. Informações retiradas do site: https://www.todospelaeducacao.org.br/. Acessado em março de 2018.

5 Fundação Lemann, de Jorge Paulo Lemann, o homem mais rico do Brasil em 2017, conforme a classificação da Revista Forbes. Lemann é um dos controladores da cervejaria Anheuser-Busch InBev e do fundo de participações 3G Capital (dono do Burger King, Americanas, Submarino, Shoptime, da Heinz, etc.).
} 
Instituto Unibanco, Itaú BBA, Santander, Suzano, Fundação Lemann, Instituto Península, Gol linhas Aéreas, Instituto Votorantin, Instituto Cyrela e Fundação Vale. Com maior ou menor protagonismo, estão entre os parceiros estão: os bancos Itaú, Unibanco, Bradesco, Santander, as empresas Gerdau, Natura, Fundação Victor Civita, Fundação Roberto Marinho, Camargo Corrêa, Instituto Inspirare/Porvir, o Instituto Península, Instituto Ayrton Senna, J. Walter Thompson Brasil (responsável pelo marketing da Cola Cola, Cargill, Bayer, Avon, Nestlé, Unilever, etc.), Grupo ABC, DM9DDB, Rede Globo, Editora Moderna, Fundação Santillana, Friends Audio, McKinsey Brazil, Microsoft, Instituto Paulo Montenegro, Banco HSBC, Futura, Editora Saraiva, BID - Banco Interamericano de Desenvolvimento, PATRI - Políticas Pública, Luzio, Itaú Cultural, Falconi, Google, etc.

O movimento TPE expressa seus objetivos e área de atuação:

Somos uma instituição cujo objetivo é contribuir, de forma decisiva, para que a oferta de Educação de qualidade passe do patamar de importante para urgente no País. Nossa atuação está estruturada em três frentes de trabalho que funcionam de maneira interligada e complementar. São elas:

\section{Políticas Educacionais}

Produz conhecimento, propõe caminhos e promove o monitoramento das metas e das políticas educacionais.

\section{Comunicação}

Divulga e promove a demanda social por Educação de qualidade, compartilhando o conhecimento gerado em nome da melhoria da Educação Básica no Brasil.

\section{Articulação e Mobilização}

Conecta o poder público e a sociedade civil em ações que valorizem a Educação (TPE, 2017).

Em vários países da América Latina foram criadas organizações empresariais similares ao TPE. Essas organizações estão articuladas em rede sob o comando do Banco Mundial. Em 2011 foi criada a Rede Latinoamericana de Organizações da Sociedade Civil para a Educação (Reduca) que atua em parceria com o Banco Interamericano de Desenvolvimento (BID) e é formada por organizações sociais de 15 países latino-americanos. Entre 2014 e 2016 a Reduca contou também com a parceria da União Europeia. Participam da Reduca: Argentina: Proyecto Educar 2050; Brasil: Todos Pela Educação; Chile: Educación 2020; Colômbia: Empresarios por la 
Educación; Equador: Grupo Faro; El Salvador: Fundación Empresarial para el Desarrollo Educativo - Fepade; Guatemala: Empresarios por la Educación; Honduras: Fundación para la Educación Ernesto Maduro Andreu - Ferema; México: Mexicanos Primero; Nicarágua: Foro Educativo Nicaragüense "Eduquemos"; Panamá: Unidos por la Educación: Paraguay: Juntos por la Educación: Perú: Empresarios por la Educación: República Dominicana: Acción por la Educación - Educa; Uruguai: ReachingU.

A questão que se coloca é: por que a grande burguesia financeira estaria interessada em promover iniciativas na educação em âmbito nacional? Tais agentes políticos privados estão ávidos por incorporar vigorosamente à educação pública a uma lógica empresarial. Uma empresa visa resultados e esses resultados podem ser medidos. Em outros termos, esses grandes grupos econômicos desejam transpor à educação pública uma ideologia de produtividade e controle. Desde a Era Vargas os agentes externos, especialmente os EUA interferem na educação brasileira (SOUZA, 2014). Mas, a aliança com o imperialismo americano foi reforçada desde a ditadura civil-militar no Brasil. Durante esse período, a Universidade de San Diego ditou os rumos de nossa educação, por meio dos acordos MEC-USAID. Instituições americanas, como a Bill and Melinda Gates Foundation, a Fundação Khan e Universidade de Stanford são importantes parceiros da Fundação Lemann.

O projeto elaborado para impulsionar as ações dessa organização foi denominado de "Compromisso Todos pela Educação". A realização do congresso intitulado "Ações de Responsabilidade Social em Educação: Melhores Práticas na América Latina" realizado em Salvador em 2006 reuniu empresários com o Ministro da Educação Fernando Haddad. Foi organizado pelo Instituto Gerdau e pelas Fundações Jacobs e Coleman (ambas com sede na Suíça). O evento resultou em planos e metas para educação que se consolidaria num pacto nacional pela educação brasileira visando ampliar a educação para que, em 2022, bicentenário da Independência do Brasil, todas as crianças e jovens tenham acesso à educação básica. Em setembro de 2006 o TPE lançou em São Paulo o documento Compromisso Todos pela 
Educação, conclamando uma "aliança intersetorial" com os representantes do governo federal, estadual e municipal, com dirigentes do Conselho Nacional de Secretários de Educação (CONSED) e da União Nacional dos Dirigentes Municipais de Educação (UNDIME), etc. O movimento passou a dirigir e coordenar ações de implementação das metas, monitorar ações e avaliar resultados.

O Plano de Metas Compromisso Todos pela Educação proposto pelos empresários da educação se consolidou por meio do Decreto n 6.094/2007 assinado pelo presidente Luiz Inácio Lula da Silva que obriga os Estados e municípios a assumirem o compromisso com a implementação das 28 diretrizes estabelecidas e realizarem um "Plano de Ações Articuladas" (PAR), sem o qual não podem participar nem receber financiamento de programas e projetos no âmbito das politicas educacionais. O Plano de Desenvolvimento da Educação-PDE (Decreto 6.094/07, Lei 12.695/12, lei 13.005/14) orientou-se pelo "compromisso Todos pela Educação"b. Foi a maior vitória do TPE, pois foi por meio do PDE que se incorporaram os objetivos e metas empresariais na educação brasileira que possibilitou novas políticas de controle empresarial das escolas, como a criação do IDEB que interfere no planejamento das escolas, balizado por índices quantitativos, aferíveis pela avaliação centralizada.

As escolas e os professores tornaram-se reféns de índices que esvaziam o sentido público da escola, reduzem o que é dado a pensar (competências em português e matemática, desconsiderando as demais dimensões da formação humana) aprofundando $O$ apartheid educacional entre as classes sociais (LEHER, 2014, p, 4).

Conforme Freitas (2012), o PDE apresenta teoricamente uma "teoria da responsabilização", meritocrática e gerencialista que se identifica com o neotecnicismo orientado pelo behaviorismo que se expressam em "[...]

\footnotetext{
${ }^{6}$ Ver SAVIANI, D. O Plano de Desenvolvimento da Educação: análise da proposta do MEC, Educ. e Soc., V. 28, n.100, Out. 2007; Evangelista, O. e Leher, R. Todos pela Educação e o episódio Costin no MEC: a pedagogia do capital em ação na política educacional brasileira, Revista Trabalho necessário, n.15/ 2012, disponível em: http://www.uff.br/trabalhonecessario/images/TN1519\%20Artigo\%20Roberto\%20Leher\%20e\%2 0Olinda\%20Evangelista.pdf).
} 
expectativas de aprendizagem medidas em testes padronizados, com ênfase nos processos de gerenciamento da força de trabalho da escola (controle pelo processo, bônus e punições)" (FREITAS, 2012, p.383). A noção de competência, conceito estreitamente vinculado à Teoria do Capital Humano ${ }^{7}$, propagado pelos organismos internacionais, foi incorporada pelos agentes do capital (Todos pela Educação, Associação Brasileira do Agronegócio/ABAG, Confederação Nacional da Indústria/CNI etc.) para a educação brasileira, limitando a educação em livros didáticos que prescrevem as competências medidas pelos sistemas centralizados de avaliação.

\begin{abstract}
O nexo entre o MEC e O TPE não é apenas conjuntural. O ministro Haddad batizou o principal plano de ação na área educacional do governo Lula da Silva, o Plano de Desenvolvimento da Educação (BRASIL, 2007b), com o nome do movimento: Compromisso Todos pela Educação. A leitura da Exposição de Motivos do Plano comprova que não se trata apenas de um ato simbólico, pois lá se afirma que as iniciativas previstas no PDE objetivam implementar as metas do TPE. Em outros termos, a principal medida educacional dos governos Lula da Silva e Dilma Rousseff é a agenda do TPE (EVANGELISTA; LEHER, 2012, p, 06).
\end{abstract}

O TPE colocou na agenda do Ministério da Educação a educação integral. Segundo o Movimento é "necessário colocar em prática a Educação integral nas áreas mais vulneráveis do país, como o campo e a periferia das metrópoles urbanas, a fim de equalizar as oportunidades educacionais." (TPE, 2012). Dessa forma incluiu no PDE, Artigo $2^{\circ}$, as diretrizes voltadas para a ampliação do tempo o PDE imbrica ações para os diferentes níveis, modalidades e etapas da educação nacional, visando constituir o que foi denominado de "visão sistêmica da educação". Em atendimento às metas do PDE constitui-se o Programa Mais Educação, seguido de outros.

Como vimos, a educação integral oferecida atualmente no Brasil surgiu de um movimento empresarial e está ligada aos interesses do imperialismo e da grande burguesia brasileira e traz consigo concepções e

\footnotetext{
7 Teoria desenvolvida nos anos de 1950 por Theodore W. Schultz na Universidade de Chigago (EUA). A ideia-chave é instrução, treinamento e educação, que corresponde a habilidades que potencializam a capacidade de trabalho e aumento da produção.
} 
ideologias vinculadas às relações de produção capitalista. O que vemos nas escolas brasileiras é a ampliação do tempo escolar de forma precária, sem infraestrutura necessária, sem investimento em recursos humanos, dentre outros graves problemas. Mas, mesmo precariamente, esses programas avançam ampliando o ideário liberal pós-moderno de educação integral em todas as esferas da educação básica apresentando dois objetivos fundamentais: culminar o processo de privatização completa da educação brasileira e aprofundar o controle ideológico do nosso povo, diante da dominação econômica, politica e cultural imposto pelos países imperialistas, especialmente pelos Estados Unidos da América.

\section{AS BASES TEÓRICAS DOS PROGRAMAS DE EDUCAÇÃO DE TEMPO INTEGRAL NO BRASIL E SEUS DETERMINANTES IDEOLÓGICOS}

Iniciaremos nossa análise pelo Programa Mais educação e Novo Mais educação oferecidos no ensino Fundamental. Inicialmente o Programa Mais Educação apresentava em seu Caderno Passo a Passo (201 la) as atividades a serem desenvolvidas, organizadas em 10 (dez) macrocampos. De sua criação em 2007 até 2014 houve algumas alterações no macrocampo e permaneceram, por fim, 7 (sete) macrocampos na proposta curricular: "Acompanhamento Pedagógico"; "Comunicação, Uso de Mídias e Cultura Digital e Tecnológica"; "Cultura, Artes e Educação Patrimonial; Educação Ambiental, Desenvolvimento Sustentável e Economia Solidária e Criativa/Educação Econômica (Educação Financeira e Fiscal)"; "Esporte e Lazer"; "Educação em Direitos Humanos"; "Promoção da Saúde" (BRASIL, 2014, p. 5-7).

O Programa Novo Mais Educação tem por objetivo "melhorar a aprendizagem em Língua Portuguesa e Matemática no ensino fundamental, por meio da ampliação da jornada escolar de crianças e adolescentes, mediante a complementação da carga horária de cinco ou quinze horas semanais no turno e contraturno escolar" (BRASIL, 2016a, art.1\%).

Esse programa se alinha ainda mais com os pressupostos dos organismos internacionais nos aspectos relacionados ao currículo. Conforme 
Silva (2017, p. 179) "as prioridades das políticas públicas de educação impostas pelo Banco Mundial, invariavelmente, elegem as disciplinas de Língua Portuguesa e Matemática como foco de atuação". As demais áreas do conhecimento são desvalorizadas, especialmente as que fomentam o pensamento crítico sobre a realidade de opressão vivida pelos trabalhadores.

Ao analisar os temas propostos por esses dois Programas implementados no ensino fundamental percebemos que a organização curricular apresenta abordagens disseminadas pelo Terceiro Setor8. Analisando o programa Mais Educação Silva (2017) e Aleprandi (2017) afirmam seu caráter mercadológico. "As questões tidas como atuais e aquelas exigidas pelo modo de produção capitalista em sua fase imperialista constituem o foco dos macrocampos do Programa Mais Educação [...]" (SILVA, 2017, p.177). Da mesma forma, Aleprandi (2017, p. 79) afirma que:

A aproximação da formação escolar à necessidade das empresas substitui constantemente a qualificação para o desenvolvimento das habilidades e competências. A formação pautada na pedagogia das competências mascara os problemas sociais inviabilizando as lutas de classe. Ocorre uma distorção na realidade imposta e os conteúdos trabalhados atuam em consonância com a lógica do mercado financeiro.

Conforme Aleprandi (2017, p. 79) as atividades de esporte e lazer são trabalhadas superficialmente com o objetivo de atrair o interesse dos jovens em permanecer na escola, o incentivo ao estudo sobre o uso de mídias, comunicação, tecnologia, busca garantir o conhecimento básico para que a população atenda ao mercado empresarial e se insira no mundo do consumo que tem como consequência o endividamento. Os indivíduos são culpabilizados por serem pobres e endividados, necessitando de Educação Financeira.

8 O termo Terceiro Setor surge "com a clara origem de classe e uma nítida função ideológica de setorializar (fragmentando) a sociedade em três instâncias supostamente desarticuladas, criando uma imagem ideológica de um suposto 'setor' autônomo e homogêneo, que seria 'popular', 'progressista', espaço da 'participação', da 'parceria' e do 'entendimento' sem conflito, sem contradição interna e que interviria ineficientemente nas respostas às necessidades sociais que o Estado vai abandonando" (MONTAÑO, 2012, p.34).

Revista Exitus, Santarém/PA, Vol. 8, №3, p. 113 - 142, SET/DEZ 2018. 
A Educação Financeira é uma forma de encobrir as relações de exploração dos trabalhadores. A pobreza seria resultado da falta de escolarização, de conhecimento e, sobretudo, da incapacidade do individuo de garantir a empregabilidade ou de criar as próprias iniciativas para superar o desemprego. Difunde-se a ideologia da autorresponsabilização pelos problemas sociais e individuais por meio da difusão de conceitos fundamentais da lógica empresarial: Empoderamento, Empreendedorismo e economia solidária.

Essas atividades devem proporcionar conhecimento, habilidades, competências e empoderamento para que os estudantes sejam protagonistas da construção e promoção de uma cultura de direitos humanos (BRASIL, 2012, p. 16. Grifos nossos).

O termo empoderamento, designa um suposto poder aos pobres, de que são partícipes com força de representação. A palavra, "O 'empoderamento' ao designar, em sua aparência, 'dar poder', acaba por despertar, à primeira vista, encantamento" (CARVALHO, 2014, p.180); "O empoderamento é apreendido pela maioria dos autores como termo, 'conceito' ou estratégia, sendo tomado como meio de fortalecimento dos sujeitos, ampliação de sua autonomia, participação cidadã, de suas habilidades e potencialidades" (CARVALHO, 2014, p.146). Porém, é um poder numa dimensão subjetiva e psicológica. No individualismo o discurso é de que o sujeito deve-se 'empoderar', 'ser empoderado' para resolver suas situações particulares. No coletivo, unir-se a outros para resolver condições por meio de Organizações não governamentais (ONGs). "Desta forma, o 'empoderamento', como projeto ideológico, procura desmobilizar as lutas de classes, desviando seu potencial transformador para a 'gerencias de conflitos'" (MONTAÑO, 2014, p.101).

Carvalho $(2014$, p.146) afirma que o empoderamento é um termo "sedutor, tendo a particularidade de se revelar objetivamente enquanto um projeto de cunho internacional vinculado às orientações do BM". "O Banco Mundial apresenta empoderamento como um processo que reforça a capacidade de indivíduos e grupos fazerem escolhas, de modo a 
transformá-las em ações e resultados almejados" (DANTAS, 2014, p.137). O indivíduo é o responsável por sua condição de vida. Desconsideram-se as condições estruturais, materiais e sócio-históricas. Paulo Freire na década de 1980 já havia introduzido o conceito de "empowerment" na obra "Medo e ousadia: o cotidiano do professor" com parceria de Ira Shor (SHOR; FREIRE, 1986). Nessa época o conceito de "empowerment" norte americano já estava sendo reproduzido pelos organismos internacionais e propagado por intelectuais alinhados à Unesco e ao Banco Mundial. O indivíduo empoderado deve ser criativo para investir, competir e se tornar empreendedor, capaz de superar individualmente os problemas do desemprego e ainda, se autoresponsabilizando pelo seu sucesso ou fracasso no emprego ou como empreendedor. O termo 'empoderar-se' transfere aos cidadãos reponsabilidades de seu sucesso e insucesso, desresponsabiliza o Estado e desonerando o capital.

Os sujeitos são convidados (feitos por um discurso do empreendedorismo) a uma apologia de crescimento e de autoemprego. Os trabalhadores já não seriam mais sujeitos sociais, pertencentes a uma classe, mais sujeitos particularizados, subjetivados. O empreendedorismo surge como forma de empoderar e autorresponsabilizar 0 indivíduo que, ideologicamente, buscará alternativas individuais e não coletivas para resolver seus problemas, atenuando a luta de classe, conforme explica Montaño (2014, p. 187):

\footnotetext{
O trabalhador passa a abandonar as lutas coletivas, a desconsiderar o desemprego, os direitos trabalhistas e os baixos salários, que não são mais vistos como questões estruturais, oriundos das contradições entre capital e trabalho, mas como consequências das suas próprias condições e capacidades pessoais. [...]. Não há mais contradição entre as classes mas diferenças entre os indivíduos.
}

O indivíduo é o responsável por sua condição de vida. Desconsideramse as condições estruturais, materiais e sócio-históricas. É uma forma de negar as contradições e a estrutura da sociedade de classes, educando para o consenso. 
No que concerne à Educação em Direitos Humanos apresenta a defesa da dignidade humana por meio do ensino escolar, mas a dignidade limita-se à igualdade jurídica e não material. Não se considera a desigualdade econômica, politica, social e a luta de classes. "Trabalha-se a tolerância e a paz para promover lutas passivas que não resultam em transformações sociais" (ALEPRANDI, 2017, p. 80).

Associado ao conceito de empreendedorismo difunde-se o ideário da Economia Solidária formada por "grupos informais" e por "associações de trabalhadores" e cooperativas, etc. Sobre a economia solidária Montaño (2014, p.189) afirma que a economia solidária é mais um canto da sereia que esconde em sua melodia a verdadeira função desse processo:

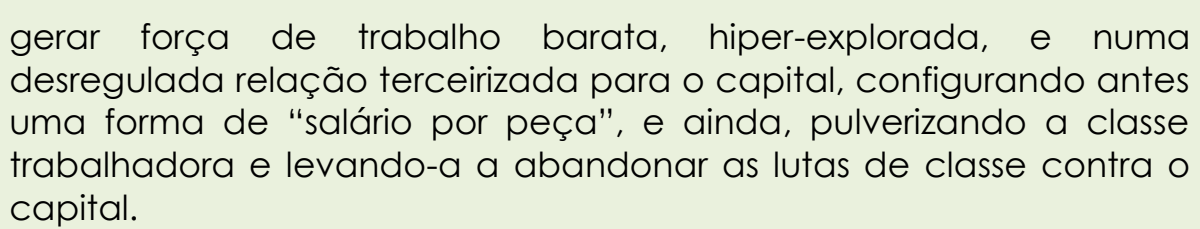
capital.

Em relação à Educação Ambiental, está associada ao conceito de desenvolvimento sustentável é um conceito gestado dentro da esfera da economia capitalista. Surgiu sob o discurso da lógica neoliberal com vistas a atender os interesses imperialistas no intuito de garantir e ampliar a exploração dos recursos naturais e seu controle sobre a Amazônia, principalmente a partir de 1992. A formulação do discurso de "desenvolvimento sustentável" foi utilizada para justificar novos projetos de financiamento de organismos internacionais, dentre eles as organizações não governamentais (ONGs) que interferem no planejamento regional a serviço do capital monopolista, possuem informações precisas sobre o território, por meio de fotos de satélites e espalham seus tentáculos por todas as atividades, graças a financiamentos de bancos e agências do capital financeiro internacional, com a finalidade de promover o "desenvolvimento sustentável" (SOUZA, 2014, p.52).

A ideologia da autorresponsabilização, da autodeterminação e do empoderamento dos indivíduos contribui para a efetivação do Estado 
mínimo, despolitiza a população e desonera o capital, servindo aos interesses da grande burguesia brasileira e ao imperialismo.

Esses conceitos empresariais reproduzidos pelo setor privado no âmbito da educação pública estão estreitamente vinculados à Pedagogia das competências que orienta todo trabalho pedagógico dos programas de educação integral. A Pedagogia das Competências reproduz os princípios do escolanovismo e do tecnicismo que se apresenta com novas roupagens fundamentadas no relativismo cultural.

A defesa de uma educação culturalista se expressa no Caderno Rede de Saberes Mais Educação: pressupostos para Projetos Pedagógicos de Educação integral (BRASIL, 2009a, p, 28). Defende-se a interculturalidade como o entrelaçamento de culturas que permita o diálogo entre diferentes "saberes", o desaparecimento da distinção entre o conhecimento científico e o cotidiano, redução das desigualdades e afirmação das diferenças, conforme Santos (1998). O texto manifesta as matrizes dos estudos Culturais a partir de autores como Nestor Cancline, Clifford Geertz, Pierre Bourdieu, Michel Focault, Boaventura de Souza Santos e Umberto Eco. (BRASIL, 2009b, p.20). As principais referências no campo da educação é Paulo Freire e seus seguidores do Instituto Paulo Freire-SP como Moacir Gadotti, Paulo Roberto Padilha, Ângela Antunes e Salete Valesan, além de Vera Maria Candau, Jaquelline Moll, Carlos Rodrigues Brandão, Sonia Kramer, etc. Esses autores são caracterizados como defensores da interculturalidade e do multiculturalismo como uma vertente das pedagogias hegemônicas pósmodernas. Os programas de ampliação do tempo escolar trouxeram uma ressignificação da tendência do escolanovismo, focando principalmente nas questões que envolvem as diferenças e pluralidade. Para Silva; Silva (2012, p. 89) é no currículo que se percebe mais a aproximação do ideário do escolanovismo, quando se propõe um formato de currículo aberto estruturado por áreas de saberes.

A Pedagogia Nova surge no final do século XIX com o objetivo de servir ao sistema produtivo, buscando superar a Pedagogia tradicional que não mais servia aos interesses do capitalismo em seu processo de 
industrialização. Havia a necessidade de preparar os indivíduos para uma sociedade dinâmica em constantes mudanças, onde o foco não é mais o produto, mas sim o processo e os métodos de alcançar o produto, ampliando a necessidade de desenvolver 0 individualismo o que altera as relações de ensino aprendizagem, assim como seu caráter social e ideológico (SOARES, 2016).

Adequando as necessidades individuais ao meio social, o objetivo central dessa pedagogia é de modelar atitudes e fortalecer o individualismo, conforme a dinâmica exigida pelo processo produtivo. Dessa forma, os sujeitos devem "aprender a aprender". Por meio de experiências, pesquisas e método de solução de problemas, ou seja, aprender fazendo. "Parte-se do concreto para o abstrato estimulando as pesquisas e experiências do cotidiano. [...] Aprender então seria modificar as percepções da realidade, pois mais importante que avaliar conhecimentos intelectuais é avaliar atitudes e habilidades" (SOARES, 2016, p. 53).

As principais características da Escola Nova é a ampla influência do pragmatismo. O norte-americano John Dewey é o maior teórico do pragmatismo na educação e da Escola Nova. Para ele o conhecimento deve-se voltar à experiência, onde as ideais só se tornam verdadeiras a partir da ação (DEWEY, 1979). O pragmatismo se opõe ao intelectualismo e promove uma guinada para as atividades manuais e físicas com o objetivo de incrementar o aprendizado prático voltado para ações efetivas e atender o sistema produtivo. A partir da década de 1960 o pragmatismo escolanovista se rearticula em novas demandas, tornando-se cada vez mais pragmático e instrumental. Essa nova fase do pragmatismo visa preparar trabalhadores para às novas tecnologias de produção, onde o produto do trabalho deve estar relacionado a determinadas habilidades e competências exigidas pelo capital. Essa faceta do pragmatismo a parece no Brasil com o nome de Pedagogia Tecnicista, que se estruturou durante a ditadura civil-militar a partir de 1964. Conforme Soares (2016, p. 54), o objetivo dessa pedagogia é "modelar o comportamento humano através de técnicas específicas, que culminassem e atendessem às exigências da 
sociedade industrial e tecnológica, ou seja, preparar mão-de-obra qualificada para o mercado", de forma a "adequar ao modelo taylorista, onde os especialistas pensam e planejam e o professor excuta, o modelo de aprendizagem é baseado no desempenho e no treinamento".

As pedagogias liberais nos últimos anos vêm apresentando novos conceitos adaptados ao mundo do trabalho e suas transformações. Esse grande leque de conceitos permeiam as relações entre educação e trabalho no que diz respeito à função social que a educação exerce ou deviria exercer. Aparecem como "novas" epistemologias reproduzidas como "saberes e competências", "habilidades", "multiculturalismo", "flexibilidade", entre outros termos utilizados, mas "são as mesmas velhas concepções tecnicistas e pragmáticas de outrora, veiculadas e reproduzidas pelo Banco Mundial, pela UNESCO, pela OIT, etc." (SOARES, 2016, p. 55). Essas pedagogias que têm mais de um século de existência aparecem com um novo sentido nesse contexto ideológico no qual predomina uma visão de mundo pós-moderna acrescida de elementos neoliberais (SAVIANI, 2002).

Assim, surgem as chamadas pedagogias liberais pós-modernas. $\mathrm{Na}$ definição de Soares (2016, p. 55) é "a junção de elementos epistemológicos das pedagogias escolanovista e tecnicista, juntamente com a releitura dos preceitos liberais e todo aparato conceitual depositado na chamada sociedade pós-moderna". Existe uma ligação explícita entre a Teoria do Capital Humano e as pedagogias liberais pós-modernas quando ambas postulam que a educação é um fator importante de desenvolvimento humano e econômico, colocando a educação como viés para equidade social e é vista como um investimento como qualquer outro produto, onde a sua função ficam reduzidas ao desenvolvimento de competências, habilidades e atitudes a serviço do sistema produtivo, e não a uma formação humana que leva os indivíduos à emancipação e transformação da sociedade (SOARES, 2016). Conforme Duarte (2010), as pedagogias liberais pós-modernas têm como tronco a pedagogia das competências que se desdobra no cognitivismo, no construtivismo, no sócioconstrutivismo. Essas pedagogias assumem várias denominações como pedagogia do 
professor reflexivo, a pedagogia de projetos, pedagogia da qualidade total, pedagogia multiculturalista, etc. Saviani (2007) as classifica como Pedagogias neoprodutivistas: neoescolanovismo, neoconstrutivismo e neotecnicismo.

Duarte (2010, p. 35) apresenta os aspectos comuns dessas pedagogias: 1) não apresentam perspectiva de superação da sociedade capitalista, o qual está associado a uma concepção idealista das relações entre educação e sociedade. 2) negação da perspectiva de totalidade, ou seja, da afirmação do princípio de que a realidade humana seria constituída de fragmentos, por acontecimentos casuais, fortuitos e inacessíveis ao conhecimento racional. Dessa negação da totalidade decorre um dos princípios centrais das pedagogias liberais pós-modernas: o relativismo (epistemológico e cultural) e; 3) negação da luta de classes.

A pedagogia das competências difunde a noção de que a escola seria capaz de promover o encontro entre formação e emprego, ou seja, a formação de competências cria o status de empregabilidade. Assim, a escola passa "a adentrar o mundo econômico como meio de se redefinirem os conteúdos de ensino e atribuir sentido pratico aos saberes escolar" (RAMOS, 2006, p. 222).

A educação integral dentro desses pressupostos deveria funcionar articulada em redes sociais que possam ampliar e descobrir novos Territórios Educativos, como preconiza o movimento Cidades Educadoras. No site do Instituto Porvir, vinculado à página eletrônica do MEC podemos encontrar na Série Educação Integral, "Os 10 pressupostos da Educação Integral". O $6^{\circ}$ pressuposto afirma que "Organizações e instituições da cidade precisam fortalecer a compreensão de que também são espaços educadores e podem agir como agentes educativos. Já a escola precisa fortalecer a compreensão de que não é o único espaço educador da cidade. ".". A educação passa a não ser mais atribuição unicamente do estado, mas da sociedade. Os programas "[...] exaltam a desresponsabilização do Estado no

${ }_{9}$ Disponível em http://porvir.org/10-pressupostos-da-educacao-integral/ 
dever de garantir o direito universal à educação pública ao apelar para a importância da família e da sociedade na garantia do direito à educação" (SILVA, 2017, p. 181). As interferências das parcerias privadas nas políticas educacionais estão aos poucos relegando a educação à lógica mercantil e, consequentemente, ao processo de privatização da educação pública.

Em relação ao ensino médio encontramos as mesmas bases conceituais encontradas nos programas do ensino fundamental.

O Programa Ensino Médio Inovador tem como objetivo promover a flexibilização do currículo, dinamizando-o no intuito de atender aos objetivos da sociedade contemporânea (BRASIL, 2013, p.10). Conforme o documento orientador, o Programa Ensino Médio Inovador surge para atender a obrigatoriedade do ensino de 04 a 17 anos até o ano de 2016, bem como a proposta de universalização do ensino médio até 2020 de jovens com faixa etária de 15 a 17 anos, conforme disposições da Emenda Constitucional $n^{\circ}$ 59, de 11 de novembro de 2009 e Meta 3 do Plano Nacional da Educação (2014-2024) respectivamente.

O programa também se organiza pedagogicamente em macrocampos especificados no documento orientador, sendo três macrocampos considerados obrigatórios e dois optativos, oferecendo no total, atividades que englobam pelo menos cinco dos macrocampos oferecidos. São eles: Acompanhamento Pedagógico (Linguagens, Matemática, Ciências Humanas e Ciências da Natureza) Iniciação Científica e Pesquisa; Leitura e Letramento; Línguas Estrangeiras; Cultura Corporal; Produção e Fruição das Artes; Comunicação, Cultura Digital e uso de Mídias; Participação Estudantil (BRASIL, 2013, p.13).

De acordo com o mesmo documento, o Programa apresenta como princípio integrar ações que englobem "Trabalho, Ciência, Cultura e Tecnologia" com vistas a proporcionar a "abordagem de conhecimentos, o desenvolvimento de experiências e a promoção de atitudes que se materializam na formação humana integral, gerando a reflexão crítica e a autonomia dos estudantes" (BRASIL, 2013, p.15-16). O programa enfatiza a necessidade de flexibilizar o currículo com conteúdos inovadores, a parceria 
público-privada, as avaliações nacionais como orientadoras das práticas de ensino, com o objetivo de atingir índices estabelecidos de desempenho escolar. A parceria publico-privada está explícita nos objetivos do programa indicando o Sistema S: "X - incentivar a articulação, por meio de parcerias, do Sistema S com as redes públicas de ensino médio estaduais" (Paragrafo único, Art. $2^{\circ}$, BRASIL, 2009C). Esse objetivo está articulado ao Programa Nacional de Acesso à Escola Técnica (PRONATEC) construído na lógica da profissionalização, da privatização e da política focal, baseada, no âmbito das suas formulações, na mesma matriz teórica, política e ideológica que orienta o aparelho estatal desde a Reforma do Estado em 1995 (SILVA JÚNIOR; LUCENA; FERREIRA, 2011). Justifica-se como democratização do ensino, mas não passa de estímulo à expansão das instituições privadas de ensino.

Para colocar de vez o Ensino Médio a serviço dos interesses do mercado capitalista, Michel Temer, aprofundando a política privatista dos governos anteriores, estabeleceu arbitrariamente, a Medida Provisória de emenda à LDB intitulada MP 746/2016 que é uma das mais agressivas medidas da chamada Reforma do Ensino Médio. A Medida Provisória N. ${ }^{\circ}$ 746/2016 foi convertida no Projeto de Lei N. ${ }^{\circ} 34 / 2016$, aprovada como Lei $N^{\circ}$ 13.415, de 16 de fevereiro de 2017 (Lei da Reforma do Ensino Médio). Para atender aos pressupostos dessa reforma, em relação à implementação da educação em tempo integral nas escolas de ensino médio das redes públicas estaduais e distritais (Art.1², BRASIL, 2016b), foi criado o Programa de Fomento às Escolas de Ensino Médio em Tempo Integral. O documento expressa os fundamentos do Programa:

$\S 10$ A proposta pedagógica das escolas de ensino médio em tempo integral terá por base a ampliação da jornada escolar e a formação integral e integrada do estudante, tanto nos aspectos cognitivos quanto nos aspectos socioemocionais, observados os seguintes pilares: aprender a conhecer, a fazer, a conviver e a ser. $\S$ 20 A pactuação com cada ente federado será formalizada por meio do preenchimento de planos de implementação e outros instrumentos a serem disponibilizados pelo Ministério da Educação MEC, tratando-se de condição para participar do Programa (Art. $1^{\circ}$, BRASIL, 2016b Grifos nossos). 
A institucionalização da formação a partir dos pilares, aprender a conhecer, apreender a fazer, aprender a conviver e aprender a ser é uma explícita adesão aos conceitos difundidos pelo Relatório Jaques Delors (1998).

No período entre 1993 e 1996 foi elaborado o relatório da comissão internacional da UNESCO, redigido por Jacques Delors, seu presidente à época. Esse documento foi publicado no Brasil em $1998 \mathrm{com}$ o apoio do Ministério da Educação. Foi a partir daí que os quatro pilares da educação e o lema "aprender a aprender" se ampliaram no discurso oficial do campo educacional. Soares (2016, p. 102 a 104, sintetiza os princípios dos quatro pilares da educação para o século XXI, conforme descreve Delors (1998): 1Aprender a Conhecer que tem por objetivo fazer o aluno adquirir um repertório de saberes necessários à vida contemporânea. Isso significa que os saberes sem utilidade devem ser substituídos por saberes utilitários. Devese valorizar o cotidiano vivido e as "percepções" por ele causadas. 2Aprender a fazer. $O$ trabalhador deve ser formado para a empregabilidade, resolver problemas, trabalhar coletivamente e buscar inovações, pois as exigências do mercado são rápidas e flexíveis. É aí que entra a noção de competências. As competências devem substituir a antiga noção de qualificação, predominante no período taylorista/fordista. A escola nesse contexto, deve desenvolver competências combinadas com qualificação profissional, atitudes e habilidades, iniciativa, habilidades de comunicação e de resolver problemas e conflitos, etc. (SOARES, 2016, p. 103). O aprender a fazer é a competência de se adaptar as novas condições laborais e ao trabalho informal. A escola deve oferecer cada vez menos conhecimentos científicos e universais e focar em valores requeridos para o mercado. 3 . Aprender a viver num mundo cada vez mais desigual. As riquezas materiais estão concentradas nas mãos de poucos. Os indivíduos querem participar da riqueza material e cultural propagadas pelos meios de comunicação, o que motiva a violência. A escola deve trabalhar para a valorização das particularidades, para impedir que as diferenças sejam tratadas como relações de poder. Nessa perspectiva, deve-se incentivar o respeito a 
diversidade e o multiculturalismo, estimulando o diálogo sem gerar conflitos no âmbito das diferenças. Os objetivos do saber viver são de fato saber evitar conflitos ou resolve-los de forma pacífica, evitar que a ofensiva dos países imperialistas sobre os países semicoloniais provoque revoltas populares e revoluções proletárias. 4. Aprender a ser, que preconiza o "cidadão participativo" na sociedade. A escola que deve estimular o aluno a resolver problemas concretos que envolvam direitos e deveres, envolver a comunidade nas decisões da escola na perspectiva de redimir conflitos e propagar os ideais de liberdade com responsabilidade, de estimular a participação da vida pública, o desenvolvimento do espírito de iniciativa e criatividade, o gosto pelo risco, etc. O ensino deve articular política e produção com o objetivo de formar o homem com capacidade de "ajustarse à produção racionalizada, constituindo-se em uma das formas pelas quais a classe burguesa busca concretizar o seu projeto hegemônico" (KUENZER, 2002, p. 60).

Outro conceito presente nas políticas de educação integral do ensino médio é o Protagonismo Juvenil. Sob o conceito de Protagonismo Juvenil foi disseminado pela CEPAL e propõe uma formação baseada da "participação" e na "solidariedade", com foco na ação individual. Esse ideário adentrou nosso país em 2003 com a formulação das Políticas para a Juventude.

A proposta curricular desse programa deverá adequar-se à Base Nacional Comum Curricular (BNCC), considerando a reforma do ensino médio (Art. 7, BRASIL, 2016b). A finalidade desse programa é "formar trabalhadores aptos à multifunção e adequados ao pensamento e interesses empresariais" (SILVA JÚNIOR, LUCENA; PEREIRA, 2011, p. 849). As concepções empresariais predominam tanto na contrarreforma do Ensino Médio, como na BNCC, pois na elaboração desses documentos estavam presentes o TPE e outros "parceiros" do setor privado. Analisando o documento da BNCC, Marsiglia; Pina; Machado; Lima (2017, p. 119) afirmam que "o documento traz uma perspectiva que visa adaptar os alunos ao mercado de trabalho ou, mais propriamente, ao "empreendedorismo". 
Essas concepções presentes nos programas de educação integral se fortaleceram ainda mais no gerenciamento Temer, que explicitamente apresenta-se muito mais vinculado aos interesses da grande burguesia brasileira e ao imperialismo ianque, editando medidas que aprofundam o processo de destruição de direitos dos trabalhadores e os mecanismos de repressão e controle social.

\section{CONSIDERAÇÕES FINAIS}

As políticas públicas orientadas pelos mercadores da educação, os organismos internacionais associadas à grande burguesia brasileira por meio de organizações como o TPE atuam formulando políticas que servem como "medida de segurança, controle social e ideológico tornando-a parte de uma estratégia que busca neutralizar movimentos contestadores da ordem capitalista. Simultaneamente, garante a formação de competências e habilidades requeridas para essa nova fase do capitalismo." (SILVA, 2017, p. 205).

Para atender aos interesses empresariais, a escola passa a ter a missão de formar indivíduos flexíveis, polivalentes que possam atender as demandas do sistema produtivo, além de formar uma grande exercito reserva de mãode-obra. E com o esgotamento do modelo fordista, e o advento do toyotismo, fez com que a educação fosse vista como uma via fundamental para se concretizar o "novo" projeto politico-econômico-social.

A institucionalização da Pedagogia das Competências com toda sua carga teórica escolanovista em sua versão pós-moderna (neopragmáticas e neotecnicistas) difunde conceitos como de empoderamento, empregabilidade, empreendedorismo, etc, na formação do trabalhador. A lógica mercadológica e empresarial propõe que ele deve arcar com seus próprios empreendimentos, que ele deve se autoresponsabilizar-se por sua condição de sucesso ou fracasso. Essa pedagogia não só se adequa à atual legislação em vigor no Brasil - no intuito de contribuir para a construção de habilidades e competências para o mercado de trabalho - mas também aborda de forma inquestionável um dos grandes pilares do conhecimento 
sintetizados pelo Relatório Jaques Delors, o de "aprender a fazer". Há uma deturpação do que seja de fato uma educação integral. O que se oferece no Brasil é uma educação de tempo ampliado a serviço do capital.

A educação na sociedade capitalista é unilateral e não forma o homem integralmente. Na concepção ampla do termo a educação integral só pode ser realizada na educação socialista onde a educação é omnilateral, forma o ser humano na sua totalidade.

Marx deixa claros os princípios pedagógicos da educação socialista: educação intelectual, física e tecnológica, que transmita os fundamentos científicos gerais de todos os processos de produção (MARX; ENGELS, 2011). Essa concepção estabelece uma relação indissociável entre ensino e trabalho produtivo. Marx (1983, p.149) destaca que "[...] o trabalho é um processo entre o homem e a natureza, um processo em que o homem, por sua própria ação, media, regula e controla seu metabolismo com a Natureza". É por meio do trabalho que o homem transforma não apenas a natureza, mas também a si mesmo. Engels (2016, p.4) defende a ideia que: "[O trabalho] é a condição básica e fundamental de toda a vida humana. Em tal grau que, até certo ponto, podemos afirmar que o trabalho criou o próprio homem". Assim, o trabalho é considerado um riquíssimo princípio educativo. A educação socialista difere radicalmente da educação burguesa não só no que diz respeito a seus objetivos, o que se compreende sem necessidade de demonstração, mas também por seus métodos. Ela está indissoluvelmente ligada ao desenvolvimento da consciência política e da cultura geral e à elevação do nível intelectual das massas. Outros povos já viveram a gloriosa experiência do socialismo, embora sabotada pelos contrarrevolucionários, mas apenas transitoriamente, pois não existe nenhuma derrota definitiva para o proletariado e outras classes populares.

A educação integral (omnilateral) só poderá ser construída com a superação do modo de produção capitalista, tarefa histórica que está sendo forjada pelo proletariado em aliança com o campesinato nessa nova e superior onda revolucionária que avança em todo o mundo. 


\section{REFERÊNCIAS}

ALEPRANDI, R. T. As políticas educacionais de educação integral no Brasil e suas relações com o mundo do trabalho. 127f. Dissertação - Universidade Federal de Rondônia, Porto Velho/RO, 2017.

BANCO MUNDIAL. El mejoramiento de la educación primaria em los países em desarrollo: examen de las opciones de política. In: Conferência de

Educação para Todos, 1990, Bangkok, Anais... Bangkok: Banco Mundial, 1990. (p. 01-271).

BRASIL. Portaria $n^{\circ} 1.144$, de 10 de outubro de 2016. Institui o Programa Novo Mais Educação, que visa melhorar a aprendizagem em língua portuguesa e matemática no ensino fundamental. Diário Oficial da União, Brasília, DF, 11 de out. 2016 a.

BRASIL. Portaria $n^{\circ} 1.145$, de 10 de outubro de 2016. Institui o Programa de Fomento à Implementação de Escolas em Tempo Integral, criada pela Medida Provisória no 746, de 22 de setembro de 2016. Diário Oficial da União, Brasília, DF, 11 de out. 2016b.

BRASIL. Portaria $n^{\circ}$ 971, de 9 de outubro de 2009 institui, o Programa Ensino Médio Inovador, com vistas a apoiar e fortalecer o desenvolvimento de propostas curriculares inovadoras nas escolas do ensino médio não profissional. Diário Oficial da União, Brasília, DF, 13 de out. 2009c

BRASIL. Portaria normativa interministerial $n^{\circ} 17$, de 24 de abril de 2007. Institui o Programa Mais Educação (...). Diário Oficial da União, Braślia, DF, 26 abr. 2007.

BRASIL. Ministério da Educação. Manual operacional de educação integral. Brasília, DF: MEC/SEB, 2014.

BRASIL. Secretaria de Educação Básica Diretoria de Currículos e Educação Integral. Manual Operacional de Educação Integral. Brasília/DF, 2012.

BRASIL. Rede de Saberes Mais Educação: pressupostos para Projetos Pedagógicos de Educação integral. Brasília, 2009a.

BRASIL. Educação Integral: texto de referência para o debate nacional. Brasilia, 2009b.

BRASIL. Programa Ensino Médio Inovador: Documento Orientador. Brasília; DF. 2013.

CARVALHO, I. O fetiche do "Empoderamento": do conceito ideológico ao projeto econômico-político. In: MONTAÑO, C. (org.). O Canto da Seria: Crítica à ideologia e aos projetos do "Terceiro Setor". SP: Cortez, 2014.

DANTAS. A. Todos pela participação: quando o consenso denuncia a dominação. In: MONTAÑO, C. (org.). O Canto da Seria: Crítica à ideologia e aos projetos do "Terceiro Setor". SP: Cortez, 2014.

DEWEY, J. Democracia e educação: introdução à filosofia da educação. $4^{\circ}$ ed. São Paulo, Nacional, 1979. 
DUARTE, N. O debate contemporâneo das teorias pedagógicas. In: DUARTE, N.; MARTINS, M. L. Formação de professores: limites contemporâneos e alternativas necessárias. São Paulo: Cultura Acadêmica, 2010.

EVANGELISTA, O.; LEHER, R. Todos pela Educação e o Episódio Costin no MEC: a pedagogia do capital em ação na política educacional brasileira.

Trabalho Necessário, Rio de Janeiro, n. 15, 2012. Disponível em: <http://www.uff.br/trabalhonecessario/images/TN1519\%20Artigo\%20Roberto \%20Leher\%20e\%200linda\%20Evangelista.pdf> .

GUZMÁN, A. La problemática nacional: discurso pronunciado no Sindicato de Docentes de Huamanga, Lima, Peru, 1974. Disponível em:

<http://www.blythe.org/peru-pcp/docs_sp/nacional.htm>. Acesso em: jan. 2009.

KOSIK. K. Dialética do concreto. Rio de Janeiro: Paz e Terra, 1976.

KUENZER, A. Z. Pedagogia da Fábrica: trabalhador. São Paulo: Cortez, 2002.

LÊNIN, V. I. O imperialismo: fase superior do capitalismo. Tradução de Olinto Beckerman. 1. Ed. São Paulo: Global, 1979.

LEHER, R. Organização, Estratégia e o Plano Nacional de Educação. p.1-23, 2014. Disponível em: <marxismo21.org/wp-content/uploads/2014/08/RLeherEstratégia>. Acesso março de 2017.

MAUÉS, O. A formação dos professores e a lógica da competências. IN: MAUÉS, O.; LIMA, R. (Org.). A lógica das competências na formação docente. Belém: EDUFPA, 2005

MARX, K. O capital. V. I, tomo 1. São Paulo: Abril Cultural, 1983.

MARX.K. ENGELS. F. Textos sobre Educação e Ensino. Campinas, SP: Navegando, 2011.

MARSIGLIA, A. C. G.; PINA, L. D.; MACHADO, V. de O.; LIMA, M. Base Nacional Comum Curricular: um novo episódio de esvaziamento da escola no Brasil. Germinal: Marxismo e Educação em Debate, Salvador, v. 9, n. 1, p. 107-121, abr. 2017.

MONTAÑO, C. (Org.). A autoação dos sujeitos: a panaceia da "participação democrática e do "empoderamento". O Canto da Sereia: Crítica à ideologia e aos projetos do "Terceiro Setor". SP: Cortez, 2014.

MONTAÑO, C. As promessas do "autoemprego". As políticas de geração de emprego e renda, o "empreendedorismo" e a "economia solidária". O

Canto da Sereia: Crítica à ideologia e aos projetos do "Terceiro Setor". SP: Cortez, 2014.

MONTAÑO, C. Pobreza, "Questão Social" e seu Enfrentamento. In: Revista Serviço Social e Sociedade. São Paulo. Editora Cortez, n. 110.2012.

SAVIANI, D. História das ideias pedagógicas no Brasil. Campinas: Autores Associados, 2007. 
SAVIANI, D. Escola e democracia: teorias da educação, curvatura da vara, onze teses sobre a educação política. Campinas, SP: Autores Associados, 2002.

RAMOS, M. N. A Pedagogia das Competências: autonomia ou adaptação? São Paulo: Cortez, 2006.

SANTOS, B. de S. Um discurso sobre as ciências. São Paulo: Cortez, 1998.

SHOR, I; FREIRE, P. Medo e Ousadia - O Cotidiano do Professor. Tradução de Adriana Lopez; revisão técnica de Lólio Lourenço de Oliveira. Rio de Janeiro: Paz e Terra, 1986.

SILVA, J. A. A; SILVA, K. N. P. Analisando a concepção de Educação Integral do governo Lula/Dilma através do Programa Mais Educação. Educação em revista. [online]. 2014, vol.30, n.1, pp. 95-126.

SILVA, P. A. D. A falácia da educação integral sob o domínio imperialista: um estudo do Programa Mais Educação em Rondônia. Tese (doutorado em educação) da Universidade Federal do Amazonas. Manaus: AM. 2017.

SILVA JÚNIOR, J. R.; LUCENA, C.; FERREIRA, L. R. As relações entre o ensino médio e a educação superior no Brasil: profissionalização e privatização Educ. Soc., Campinas, v. 32, n. 1 16, p. 839-856, jul.-set. 2011 . Disponível em http://www.cedes.unicamp.br, acessado em 20 de junho de 2016.

SOARES, G. H. M. A Teoria do Capital Humano e as pedagogias liberais pósmodernas presentes nas políticas de formação de professores. 157f.

Dissertação - Universidade Federal de Rondônia, Porto Velho/RO, 2016.

SOUZA. M. M. Imperialismo e Educação do Campo. Araraquara-SP: Cultura Acadêmica, 2014.

SOUZA, M. M.; ALEPRANDI, R. T.; TRENTINI, S. S. A. As concepções filosóficas e pedagógicas de educação integral no Brasil e as políticas educacionais. IN: COSTA, S.A; COLARES, M.L.I.S. (Orgs). Educação Integral: concepções e práticas a luz dos condicionantes singulares e universais. Curitiba: CRV, 2016. TPE - TODOS PELA EDUCAÇÃO. Quem somos. 2017. Disponível em: https://www.todospelaeducacao.org.br/quem-somos/como-atua/

TPE. "Um bom professor, um bom começo" é a nova campanha do movimento todos pela educação. Releases. 12 de abril de 2011 . [S.I], 2011.

TRENTINI, S. S. A. Educação integral ou educação de tempo integral? Uma análise da teoria e da prática do Programa Mais Educação nas experiências das escolas da rede estadual na Zona da Mata rondoniense. $220 f$. Dissertação - Universidade Federal de Rondônia, Porto Velho/RO, 2017.

Recebido em: Fevereiro de 2018 Aprovado em: Julho de 2018 